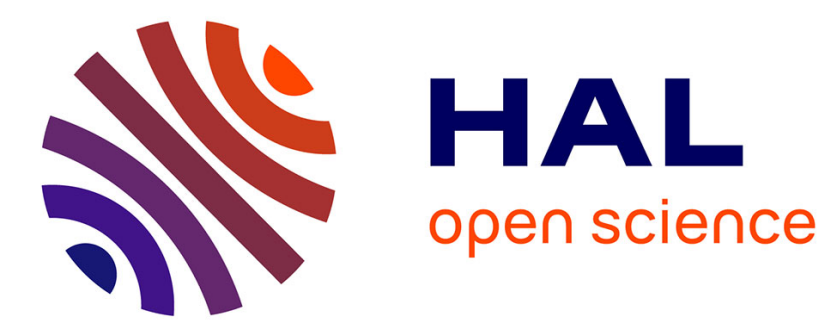

\title{
Anti-Buckling Device for Ultra-Thin Metallic Sheets Under Large and Reversed Shear Strain Paths
}

\author{
C. H. Pham, F. Adzima, J. Coer, P. Y. Manach
}

\section{To cite this version:}

C. H. Pham, F. Adzima, J. Coer, P. Y. Manach. Anti-Buckling Device for Ultra-Thin Metallic Sheets Under Large and Reversed Shear Strain Paths. Experimental Mechanics, 2017, 57 (4), pp.593-602. 10.1007/s11340-017-0256-4 . hal-01697279

\section{HAL Id: hal-01697279 \\ https://hal.science/hal-01697279}

Submitted on 13 Jul 2018

HAL is a multi-disciplinary open access archive for the deposit and dissemination of scientific research documents, whether they are published or not. The documents may come from teaching and research institutions in France or abroad, or from public or private research centers.
L'archive ouverte pluridisciplinaire HAL, est destinée au dépôt et à la diffusion de documents scientifiques de niveau recherche, publiés ou non, émanant des établissements d'enseignement et de recherche français ou étrangers, des laboratoires publics ou privés. 


\title{
Anti-Buckling Device for Ultra-Thin Metallic Sheets Under Large and Reversed Shear Strain Paths
}

\author{
C.H. Pham ${ }^{1}$ - F. Adzima ${ }^{2} \cdot$ J. Coër ${ }^{1}$ - P.Y. Manach ${ }^{1}$
}

\begin{abstract}
The kinematic contribution to the hardening of ultra-thin metallic sheets characterized by monotonic and reversed simple shear tests is of high interest in the sheet metal forming industry, because of its influence on the accurate prediction of springback. However, ultra-thin sheets are very sensitive to buckling when submitted to shear stress because of the large gauge width to thickness ratio, the stress perturbations induced by the clamping and the alignment of sample, which thus limit the attainable strain levels using conventional simple shear devices. In this paper, a new simple shear test dedicated to ultra-thin metallic sheets is proposed through the development of a specific support. A transparent glass part enables the application of a normal tightening force to prevent the out-of-plane buckling of the sheets whilst also allowing full field strain measurements to be taken. Firstly, the capabilities of the device are shown by comparing the mechanical behavior in a simple shear test on an austenitic stainless steel with and without the support. A good reproducibility of the flow curves is observed with the support and large shear strains are reached without buckling. Secondly, the influence of friction due to the contact between the sample and the support is checked by finite elements simulations and shown to be negligible compared to the shearing force. Finally, monotonic and reversed shear tests on a pure copper sheet with a thickness of $0.1 \mathrm{~mm}$
\end{abstract}

P.Y. Manach

pierre-yves.manach@univ-ubs.fr

1 Univ. Bretagne Sud, FRE CNRS 3744, IRDL, 56100 Lorient, France

2 Arts et Métiers Paristech, UMR CNRS 7239, LEM3, 57045 Metz, France were performed up to rupture without buckling, these were not previously conceivable on such a low thichness, and demonstrate the potential of the proposed device.

Keywords Simple shear test · Ultra-thin sheet · Stainless steel $\cdot \mathrm{Cu}$ alloy $\cdot$ Buckling $\cdot$ Bauschinger effect

\section{Introduction}

The forming of very small metallic parts by plastic deformation is playing an increasingly key-role in manufacturing [1]. Due to the trend of miniaturization in high technology fields like micro-electronics, ultra-thin metallic sheets are widely used $[2,3]$, particularly $\mathrm{Cu}$ alloys due to its good electrical and thermal conductivity and malleability [4, 5]. The fabrication processes of small parts [6], i.e. those having dimensions between 2 and $20 \mathrm{~mm}$ [7], with ultra-thin sheets, lead to low production cost and low energy consumption compared to those of larger parts [8,9]. The latest development in forming processes have demonstrated that progressive die micro-stamping may be used to plastically deform ultra-thin sheets [10]. In successive stages, the metal strip is punched and bent successively to obtain the finished part. The band enters the tool that then closes: firstly, the strip is clamped between the blank-holder and the die and in a second step, the punches cut or fold the material. The tool opens, the band moves a step forward through the tape guide and the cycle continues until the workpiece reaches its final shape. Between each step of the forming process, the material is subjected to the opening and closing of the tools that generates a release of the stresses that produces springback and a succession of loading-unloading or even reloading. In such cases, the numerical simulation of the forming process of ultra-thin metallic components may require a 
fine modeling of the constitutive behavior. This is particularly important in progressive die micro-stamping processes [11], regardless of the retained constitutive approach that could use phenomenological, mean field or crystal plasticity models.

As is common in many industrial fields, the simulation of micro-forming processes is currently based on the mechanical properties measured in tensile tests but the actual results are still far from those of the experimental results $[1,12]$. From manufacturers, the thickness of the material is what determines whether it is called ultra-thin sheet, thin sheet, or even plate, and ultra-thin sheets have usually a thickness ranging from $13 \mu \mathrm{m}$ up to $200 \mu \mathrm{m}$. But this division depends also on the ratio $N=t / d$ between the thickness $t$ and the average grain size $d$. When this ratio decreases down to 10 or lower, which is the case of both materials considered in this study, the mechanical behavior is strongly affected. Therefore, there are specificities of ultra-thin sheets that are revealed when the material thickness decreases and prevents the use of previous knowledge acquired from traditional methods and thicknesses. First of all, the material behavior is strongly influenced by the so-called size effect $[13,14]$ : the yield stress decreases following the increase of the proportion of surface grain with respect to the total number of grains. The anisotropy is modified and the strain in the thickness becomes predominant [6]. The decrease in ductility is even more dramatic, falling almost to zero for very low thicknesses, with a change of necking and rupture modes [15]. The relative contribution of friction increases significantly (up to a factor 20) when the size of the parts decreases [16]. Friction is a microstructural effect arising from the micro geometry, especially the surface roughness. As observed by numerous authors, the friction coefficient increases with decreasing size, resulting in an increased influence of the friction on the measured flow stress. Finally, a large dispersion of the mechanical properties is systematically noted, the overall behavior becoming more dependent on the individual behavior of each grain compared to polycrystalline materials. However, from a macroscopical point of view, the mechanical behavior of metallic sheets is usually modeled within a large deformation framework and using elasticplastic models. During stamping and springback processes of ultra-thin sheets, the material is affected by various deformation modes such as stretching, shearing, bending, and unbending [8]. If the material exhibits a significant Bauschinger effect, mixed hardening models should be considered to represent its mechanical behavior [17]. For all these reasons, to increase the accuracy of the numerical predictions and in particular for springback, a database of the mechanical properties of ultra-thin metallic material should include not only tensile stress-strain curves but also reverse loading sequences.
Several methods have been developed to test materials along reverse loading paths. In-plane compression can be performed using standard samples together with side constraints or loads to avoid buckling in the thickness direction [18-22]. However these methods are unable to generate large strains because of buckling outside of the supported region, particularly when dealing with ultra-thin sheets. Reverse torsion [23] or a combination of torsion and tension [24] has also been used successfully to reach high strains. But the sample preparation requires the sheet to be welded into a thin-walled tube, and such operations can change the microstructure of the sheet, thus altering its macroscopic properties. Another disadvantage of torsion testing is that stress and strain are not uniform throughout the cross section of the sample, requiring the strain gradient in the radial direction to be taken into account [25].

Planar simple shear tests become a common practice in the characterization of metallic material in sheet form [26-28]. Unfortunately, the large gauge-width to thickness ratio of classical devices, the width of which is necessary to reach a sufficient accuracy in the strain measurement, and the non-homogeneity of shear deformation in ultra-thin sheet leads to unwanted side-effects such as the development of out-of-plane buckling of the sheet [29]. According to the knowledge of the authors, in shear tests, unlike in tension tests, no specific tools or devices have been developed to prevent this phenomenon. In this paper, a new simple shear test dedicated to ultra-thin metallic sheets is proposed through the development of a specific support. A transparent glass part enables a normal tightening force to be applied to prevent the out-of-plane buckling of the sheets while also allowing full field strain measurements to be taken. Firstly, the principle of the planar simple test is recalled, and next the parameters that lead to the occurrence of buckling in shear. Then, the capabilities of the device are demonstrated by comparing the mechanical behavior in a simple shear test on an austenitic stainless steel, with and without the support. The influence of friction due to the contact between the sample and the support is checked by finite elements simulations and finally, monotonic and reversed shear tests on a pure copper sheet of $0.1 \mathrm{~mm}$ thick are performed up to rupture without buckling to demonstrate the potential of the proposed device.

\section{Planar Shear Test}

The device, presented in detail in $[26,28]$ is directly connected to a tensile test machine. Samples are rectangular with a length of $L=30 \mathrm{~mm}$ and a width of $l=15 \mathrm{~mm}$. The samples are set in the shear device and clamped at both sides, such that a planar load distribution is applied along the grip length (see Fig. 1). The grips are screwed with a 
Fig. 1 On the left-hand side, schematic drawing of a shear test sample, before and after shearing. On the right-hand side, representation of the stress distribution $\sigma_{n}$ along the clamped edges, highlighting the tension ( $\mathrm{t}$ ) and compression (c) state corners as well as the area of strain measurement
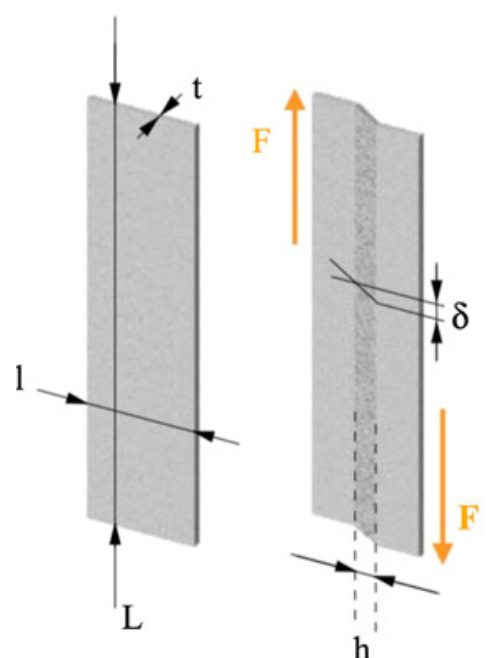

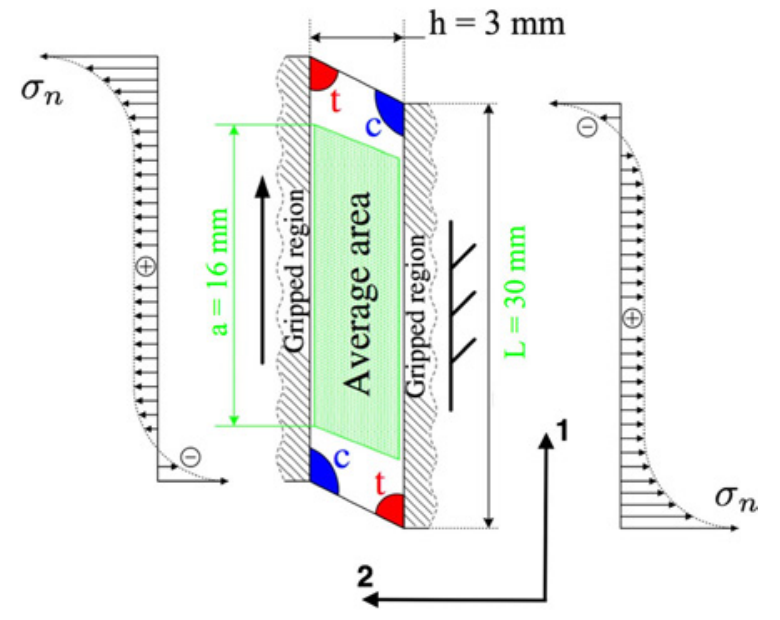

torque wrench and after several trials, a suitable torque is applied to minimize the sliding between the specimen and the grips. One grip moves upwards while the other remains fixed, inducing a simple shear deformation in the gauge width $h$ between the movable and the fixed grips. To impose the condition $h$ constant for a simple shear deformation, the moving grip cannot move laterally (along the horizontal axis). The rolling direction is aligned with the shear direction. The simple shear tests have been carried out at room temperature at a constant strain rate $\dot{\gamma}=10^{-3} \mathrm{~s}^{-1}$.

The shear strain measurement is made using a noncontacting 3D optical system (Aramis 5M, GOM, Germany). Two video cameras (8-bit gray levels, $2050 \times 2448$ pixels images at $15 \mathrm{~Hz}$ maximum) record the motion of a random pattern spray painted on the sample surface, by means of digital image correlation (DIC) technique. The complete gauge area of the sample is observable by the cameras: the number of non-overlapped subsets defined on this zone, which corresponds to the size of the virtual grid used in DIC is $4-5$ wide and 100 long. The subset size is $11 \times 11$ pixels square leading to a scaling value in the range of $15-18$ pixels $/ \mathrm{mm}$. The measurement is performed with a step size of 8 pixels which corresponds to an overlap of $70 \%$. The shear strain field measured by DIC is fairly homogeneous on the specimen, but inevitable edge effects are observed near the free edges of the specimen, due to the stress distribution on the borders (see Fig. 1). So, the shear strain $\gamma$ is calculated as the average of the shear strain field in the homogeneous zone (named average area in Fig. 1), i.e. by removing the values near the free edges. The average area is depicted in Fig. 1 and the length $\mathrm{a}=16 \mathrm{~mm}$. The accuracy of this measurement is of the order of $10^{-4}$ [30].

The kinematics of the simple shear test can be described by the transformation gradient $\boldsymbol{F}$ :

$\boldsymbol{F}=\boldsymbol{I}+F_{12} \mathbf{1} \otimes \mathbf{2}$
Using this kinematics, the planar shear component of the Cauchy stress tensor can be deduced from the measurement with the load cell of the tensile test machine of the actual force $F$ such as $\tau=F / L t$, where $t$ is the thickness of the sample, $\boldsymbol{I}$ is the second order identity tensor, $\mathbf{1}$ is parallel to the shear direction and $\mathbf{2}$ perpendicular to $\mathbf{1}$ in the sheet plane. The test is controlled by the evolution of $F_{12}$ with time. Due to the edge effects, the Cauchy stress tensor also involves tensile components. In the frame $(\mathbf{1}, \mathbf{2}, \mathbf{3})$, where $\mathbf{3}$ is the normal direction, it can be written:

$\boldsymbol{\sigma}=\left(\begin{array}{ccc}\sigma_{11} & \tau & 0 \\ \tau & \sigma_{22} & 0 \\ 0 & 0 & 0\end{array}\right)$

The components $\sigma_{11}$ and $\sigma_{22}$ (whose distribution is denoted by $\sigma_{n}$ in Fig. 1) are not equal to zero due to the imposed conditions that $L$ and $h$ are constants, which generates lateral compression forces that can reach high values near the free ends of the sample. But these stresses can be disregarded by using a large length-over-width ratio $L / h$ [27]. It should be emphasized that in shear, the displacement necessary to reach a large deformation is rather limited compared to tension-compression. For example, by using a shear width of $3 \mathrm{~mm}$, a displacement of $1.5 \mathrm{~mm}$ generates a shear strain of 0.5 , while in tension using a classical gauge length of $12.5 \mathrm{~mm}$, a displacement of $2.5 \mathrm{~mm}$ is required to obtained a strain of 0.2 .

\section{Origin of Buckling}

Unlike the problem of normal buckling, the shear buckling of plates is mathematically described by differential equations having a term with an odd order of derivatives with respect to each of the planar spatial coordinates. Therefore, their governing equations cannot be solved exactly, except 
in the case of an infinite length of one side of the rectangular plate [31]. In our samples, the length is systematically large compared to the width and the thickness. Using the Young's modulus and Poisson's coefficient denoted by $E$ and $v$ respectively, the Euler shear buckling stress is obtained by the following relation:

$\tau_{E}=\frac{\pi^{2} E}{12\left(1-v^{2}\right)}\left(\frac{t}{h}\right)^{2} k_{s}$

The value of $k_{s}=8.98$ depends on the $L$ and $h$ of the long and short sides of the shear zone through $\alpha=L / h$ the sample aspect ratio. Its value has been determined by [31] for the theoretical buckling stress in shear of a clamped rectangular plate of an infinitely long strip. So, the critical buckling stress $\tau_{E}$ for which buckling occurs is conversely proportional to the square of the buckling length, which depends on the width of the sheared area and on the clamping, and is proportional to the square of the thickness of the specimen [27, 29].

Since the thickness is essentially determined for a rolled sheet, and considering the material properties of the sample, the condition of avoiding buckling is essentially to limit the width $h$ of the specimen. Unfortunately, with our device [28], the width of the shear zone cannot be decreased to less than $1.4 \mathrm{~mm}$ since the shear zone becomes too narrow to access the shear strain by DIC. For ultra-thin copper sheets considered in this study ( $t=0.1 \mathrm{~mm})$, the critical buckling stress is lower than the yield stress $\left(\tau_{y}=141 \mathrm{MPa}\right)$ regardless of the width $h>1.4 \mathrm{~mm}$. Then, it was not possible to perform any planar shear tests on this material with such a thickness. So, as classically performed in tensioncompression [19], the main idea was to develop a specific device in order to apply a slight normal force to prevent buckling.

Recently, several solutions have been developed using a hydraulic actuator operating on the specimen inserted between the supporting blocks [18, 20]. Another solution has been proposed for the side-supporting fixture which is to implement sliding blocks with angular chamfers [21], while in [22] a clamping force was applied to the springs to support the tested samples. Since in all these solutions the side force and the friction coefficient needs to be known, the friction force can be approximately calculated on the basis of Coulomb law assuming a constant coefficient. However, such hypotheses have to be treated cautiously because of the large increase of the surface roughness of the sample, that leads to a non-constant friction coefficient [16].

\section{Anti-Buckling Device}

To generate a lateral force in the thickness direction to prevent buckling, a support is composed of two plates applied in contact with both sides of the shear zone. On one side, the plate is transparent in order to enable the measurement of the shear strain by digital image correlation. The support is composed of 8 parts as presented in Fig. 2. The rear plate (1) made of aluminum with the dimensions $60 \times 2.8 \times 4.0 \mathrm{~mm}^{3}$ (length, width, thickness respectively). The front plate (2) made of glass, with the dimensions $40 \times 2.8 \times 4.0 \mathrm{~mm}^{3}$ (length, width, thickness respectively). Glass with the lowest refractive index was selected in order to prevent errors in the measurement of strain. The specimen is set between these two plates. M2 screws (8) and nuts (7) are used to clamp both plates via the clamping plates (3) and plastic rods (6). The shims (2) have a thickness equal to the sum of those of the glass plate and the sample, while the plastic rods (6) prevent the tightening force from breaking the glass plate. In order to limit the friction between the aluminum plate and the sample, Castrol LMX grease was used for lubrication. The tightening force is controlled by a torque wrench and set by the trial-and-error method to the value 1.25 Nm. The positioning of the support in the shearing device $[26,28]$ is presented in Fig. 2 and corresponds exactly to the distance between both grips of the machine.

In order to validate the support, the first step consists of comparing the results obtained with and without the support. To do so, a reference material was chosen to calibrate the device, whose mechanical properties and thickness resides within the range where the variation of $h$ leads to either buckling or not. This enables the determination of the influence of the use of the device on stress-strain curves and if large strains are achievable. A stainless steel sheet AISI 304 of $0.15 \mathrm{~mm}$ thick was selected for this test, which average grain size measured by EBSD is $19 \mu \mathrm{m}$, leading to a ratio $N=t / d=8$ characteristic of an ultra-thin sheet. Due to the mechanical properties of this material presented in Table 1, the sample exhibited buckling in shear for a width $h$ greater than $1.4 \mathrm{~mm}$ as can be observed in Fig. 3). Using the support, it can be observed in Fig. 3 that the shear width can be set to $3 \mathrm{~mm}$ and from Fig. 4 that the shear strain $\gamma$ could reach 0.5 without any occurrence of buckling.

Figure 4 presents the flow curves obtained for monotonous shear tests with and without the support. For tests without the support, $h$ varies from $2.2 \mathrm{~mm}$ down to $1.4 \mathrm{~mm}$, for which the samples do not present any buckling effect for a strain up to $\gamma=0.7$. However, the results are scattered with an uncertainty of $\pm 20 \mathrm{MPa}$, corresponding to $10 \%$ of the shear stress for $\gamma=0.5$. This dispersion increases when the thickness of the sheet or the yield strength decreases [32]. In addition, the quality of the strain measurement is poor due to the narrowness of the shear zone leading to reduced size of the gauge area observable by the DIC system. When using the support, shear tests can be performed successfully up to a width $h=3 \mathrm{~mm}$ and until $\gamma=0.5$, no buckling effect is observed on the sample 
Fig. 2 Shear test support for ultra-thin sheets. Left-hand side: description of the device: (1) aluminum plate, (2) front plate, (3) clamping plate, (4) transparent glass plate, (5) sample, (6) plastic rod, (7) nuts, (8) screws. Right-hand side: positioning of the support into the shear device (the left grip is removed for clarity reasons)

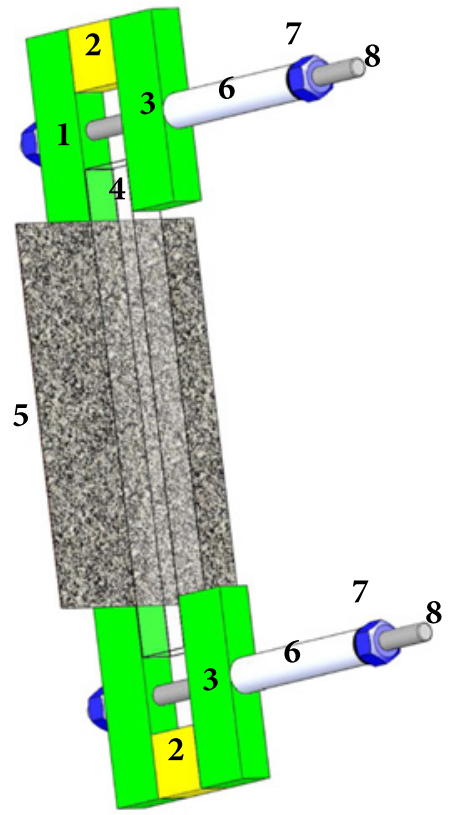

(Fig. 4). Conversely, a very good reproducibility is obtained for the tests performed with a narrower shear zone. In addition, by comparing these results with the results obtained for $h=1.4 \mathrm{~mm}$ without the support, a good correlation between these tests was observed, but the accuracy of the strain measurement was higher using the support.

Then, the comparison between the shear tests of the AISI 304 ultra-thin stainless sheet, with and without the support, shows some capabilities of the device as well as its benefits for ultra-thin sheet shear testing. Note that the influence of the refractive index of the glass part has been checked to be negligible on the measurement of the shear strain.

\section{Results and Discussion}

Following the previous results, the support was then used to perform shear tests on ultra-thin pure copper sheets $(99.9 \%$ $\mathrm{Cu}$ ) with a thickness of $0.10 \mathrm{~mm}$. An average grain size of $10 \mu \mathrm{m}$ has been measured by EBSD, leading to $N=10$ characteristic of an ultra-thin sheet. In fact, the achievement of shear tests for this material and such a thickness is impossible because of the onset of buckling for early shear strains,

Table 1 Measured mechanical properties of the studied AISI 304 stainless steel

\begin{tabular}{llll}
\hline YS (MPa) & UTS (MPa) & $r$ & $n$ \\
\hline 320 & 704 & 0.899 & 0.6 \\
\hline
\end{tabular}

even for a width $h$ less than $1.0 \mathrm{~mm}$. The mechanical properties of this material are given in Table 2 and $E=137$ GPa and $v=0.34$. Figure 5 presents the virgin samples, and those obtained after shearing without and with the support for $h=3 \mathrm{~mm}$.

The samples, of initial dimensions $30 \times 15 \mathrm{~mm}^{2}$, are cut directly into the sheet in the rolling direction. One of the two surfaces of the sample is painted with a layer of black and white speckle for measuring the shear strain using the DIC system (Aramis) (Fig. 5). The other side is lubricated with Castrol LMX grease in order to reduce friction with the aluminum support. Figure 5 shows that without the support, the sample demonstrates an extensive buckling all over the gauge area for $h=3 \mathrm{~mm}$. Conversely, with the support, the shear strain could reach $\gamma=0.25$ without any occurrence of buckling.

Figure 6 presents the flow curves obtained for monotonous shear tests with the support. Due to its purity, the hardening of this material is particularly weak (see $n$ coefficient in Table 2) and the flow curves are close to a prefect plastic material. This hardening is conducive to the development of geometric instabilities and thus the onset of buckling, even for small shear strains. It is observed that the three tests present a good reproducibility, within the range of discrepancy that is generally recorded in shear tests [28]. The capabilities of the support are then confirmed and the following sections present the results to evaluate the influence of the proposed device on the test results. The homogeneity of the shear strain in the gauge area and the influence of the tightening force of the support are studied. 
Fig. 3 Planar simple shear test on AISI 304 stainless steel sheet. From left to right: width $h=2.2 \mathrm{~mm}$ without support, $h=1.4 \mathrm{~mm}$ without support and $h=3 \mathrm{~mm}$ with support. The black and white speckle is for the shear strain measurement with the DIC system. Buckling effects occur only in the left case
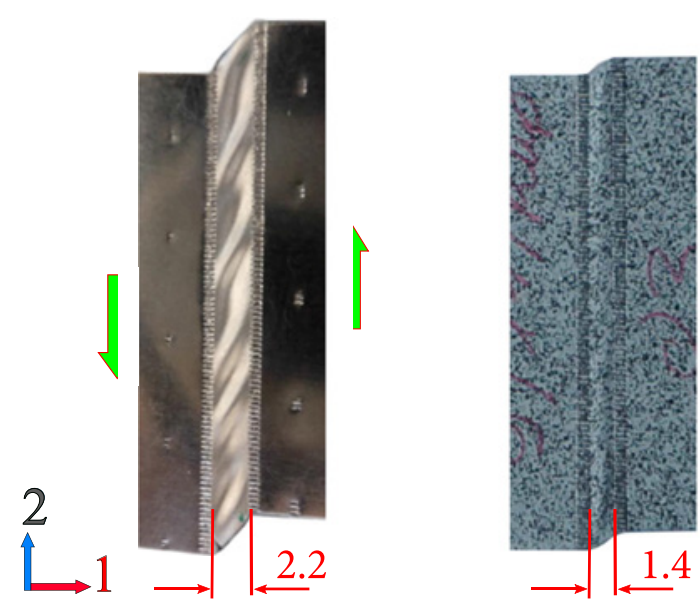

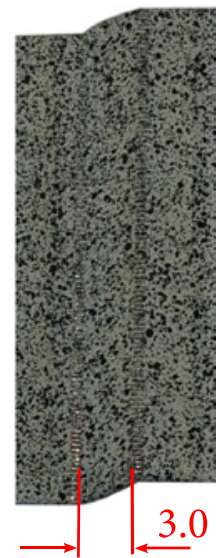

\section{Homogeneity of the Strain}

The shear strain $\gamma=2 \varepsilon_{x y}$ corresponding to the nondiagonal component of the planar transformation gradient is measured with the DIC system over the entire gauge area, and is then calculated as an average value over a rectangular zone on the sample surface presented Fig. 7. To investigate the homogeneity of strain over the gauge area, the shear strain evolution is analyzed along three sections. The distance between two successive sections is $0.5 \mathrm{~mm}$. Figure 7 shows the strain distribution determined after testing sheets of $\mathrm{Cu} 0.1 \mathrm{~mm}$ thick to several average shear strain values $\gamma=0.078,0.136,0.196$. It can be seen that there is a zone of nearly constant shear strain in the center region of the gauge area while towards the ends the shear strain becomes non-uniform. According to [33], the difference of calculating the average of the shear strain over the full length of the gauge area or over a reduced area is negligible. This leads

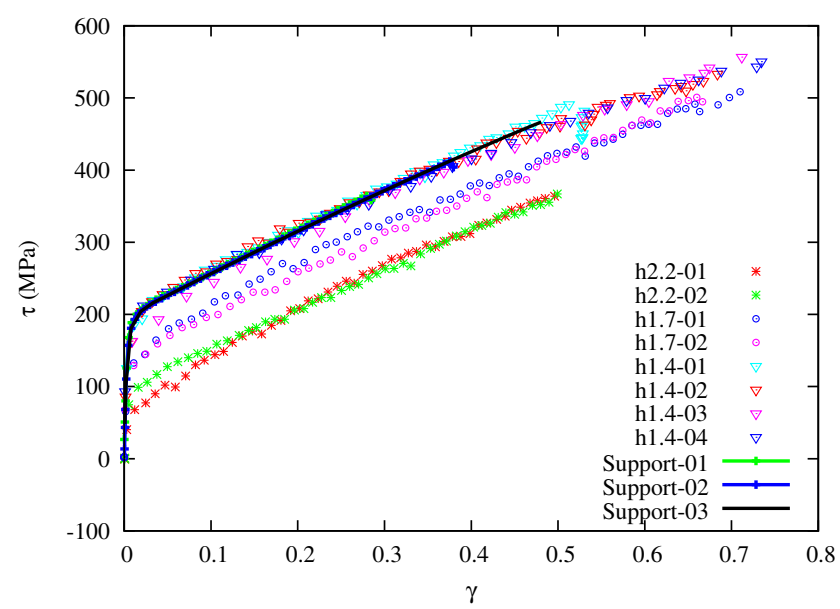

Fig. 4 Comparison of shear stress-strain curves obtained with or without support (hx.x indicates the width used for the tests without support) to a strain tensor that is close to the radial path in the principal strain space and material anisotropy may therefore only have a minor effect on the material response in forward and reverse shear.

\section{Influence of the Tightening Force}

To carry out the tests with the support, the aluminum and glass plates are tightened together during the tests. The clamping force between the two plates is limited by the contra-plate (2) and the plastic rods (6) and is controlled by the screws (8) (see Fig. 2). Even if experimentally the contact between the sample and the aluminum plate has been lubricated in order to limit friction, the influence of the clamping force of the support has to be checked. However, a direct measurement of this force is hard to achieve and it is not possible to determine whether it evolves during testing. So the numerical prediction of the tightening force is an effective way to determine its evolution.

The gauge area of the sample is modeled by a rectangular plate of $30 \mathrm{~mm}$ long and $3 \mathrm{~mm}$ wide. Solid elements with linear interpolation and reduced integration of Abaqus Explicit (C3D8R) are used. The sheet is meshed with three layers in the thickness and the element size is $0.1 \times 0.1 \mathrm{~mm}^{2}$ in the sheet plane. To reproduce the buckling effect, a small defect is generated before shearing the sample. The left side of the sample presented in Fig. 8 is clamped, while the right side moves slightly $(0.005 \mathrm{~mm})$ in the $\mathbf{z}$ direction. Then this side is moved in the $\mathbf{y}$ direction in order to shear the sample in the plane, but also out-of-plane due to the a small amount of $\mathbf{z}$ displacement. The width of the

Table 2 Measured mechanical properties of the pure copper material

\begin{tabular}{llllll}
\hline E (GPa) & YS (MPa) & UTS (MPa) & $v$ & $\bar{r}$ & $n$ \\
\hline 137 & 245 & 285 & 0.34 & 0.674 & 0.31 \\
\hline
\end{tabular}



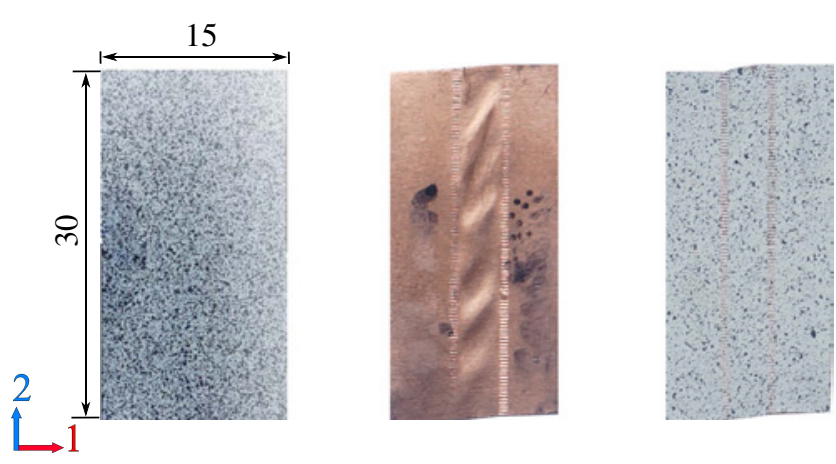

Fig. 5 Planar simple shear samples of $\mathrm{Cu}$ sheets with a thickness of $0.1 \mathrm{~mm}$. From left to right: dimensions of the virgin sample, shear test without support and with the support for a width $h=3 \mathrm{~mm}$. Buckling effects occur in the middle case (out-of-plane waves), as long as the support is not used

specimen is kept constant during the numerical simulation. Using these boundary conditions, the sample buckles after a small amount of deformation $\gamma=0.07$ as it can be observed in Fig. 8.

In order to represent the action of the support, two rigid plates are added to the numerical model, on both free surfaces of the sample. These two plates $2.8 \mathrm{~mm}$ wide are meshed by rigid elements R3D4. A tightening force is applied to the plates during the simulation. As the contact between the sample and the support is lubricated, the conditions of contact-friction between the blank and the support are defined as a common practice in sheet metal forming processes, by the penalty method associated with the Coulomb friction law, with a weak friction coefficient of 0.05 . The same boundary conditions as the previous simulation, including the out-of-plane movement, are applied to the sample. In this configuration, no buckling effects are observed up to large shear strain $(\gamma=0.3)$.

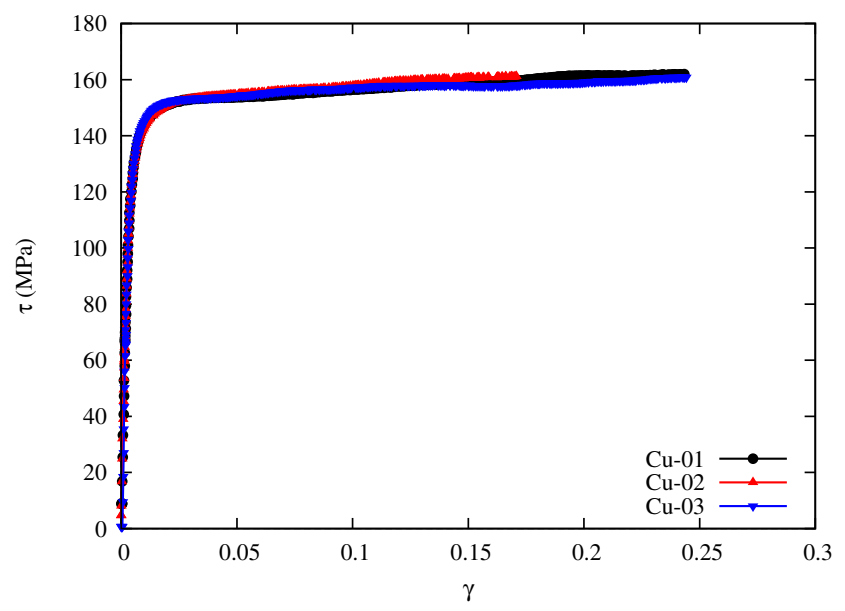

Fig. 6 Reproducibility of the simple shear tests on the pure copper sheet with a thickness of $0.1 \mathrm{~mm}$
Two different values of the clamping force are applied on the support, i.e. $F_{c}=45 \mathrm{~N}$ and $90 \mathrm{~N}$. These values have been estimated analytically according to the resistance of the plastic rods (parts 6 in Fig. 2). They correspond respectively to a compression stress of $16 \mathrm{MPa}$ and $32 \mathrm{MPa}$ in the plastic rods, chosen from the range of variation found in the literature of the yield stress of the polymer. The reaction forces in the $\mathbf{y}$ direction for nodes outside the shearing boundary conditions, are extracted and plotted as a function of the displacement of the lateral side of the sample in Fig. 9. Obviously, the results show that the greater the clamping force, the greater the reaction forces in the $\mathbf{y}$ direction, but in both cases ( $45 \mathrm{~N}$ and $90 \mathrm{~N}$ ), it remains weak compared to the shearing force (less than $1 \%$ ) that are superimposed.

\section{Reversed Shear Tests}

The previous results have confirmed the capabilities of the proposed support in the achievement of shear tests on ultrathin metallic sheets. As a final example of the potential of the device, reversed shear tests are performed. Many authors have pointed out the importance of considering the Bauschinger effect in numerical simulations of sheet metal forming, by using a mixed isotropic-kinematic hardening law instead of purely isotropic hardening, e.g. [5, 34]. The Bauschinger effect corresponds to early re-yielding under reversed loading with a rounded yield point, followed by a transient stage before the onset of stable work-hardening. Particularly in the case of ultra-thin metallic sheets, the taking into account of mixed hardening is a key-point to master the springback effect [35]. Some commercial Finite Element Analysis (FEA) softwares already enables the direct incorporation of tension-compression test data for advanced model development but buckling and frictional effects limit the test to weak reverse strain levels. The planar simple shear test provide an alternative solution since it gives complementary informations to determine yield functions and reversed tests can be performed to identify the kinematic hardening contribution.

Reversed shear tests were performed to highlight the Bauschinger effect of the pure copper material in order to evaluate its kinematic work-hardening. These tests, presented in Fig. 10, are composed of a loading up to several values of $\gamma(0.02,0.05,0.1)$ followed by a loading in the opposite direction until rupture. In order to highlight differences between the first and the second strain path, the curves are also plotted in a positive quadrant (in dashed lines), i.e. the shear strain is the cumulated shear strain along both paths while the shear stress is its absolute value. For comparison, the results obtained in a monotonic shear test under the same experimental conditions are superimposed on the figure (black curve). 

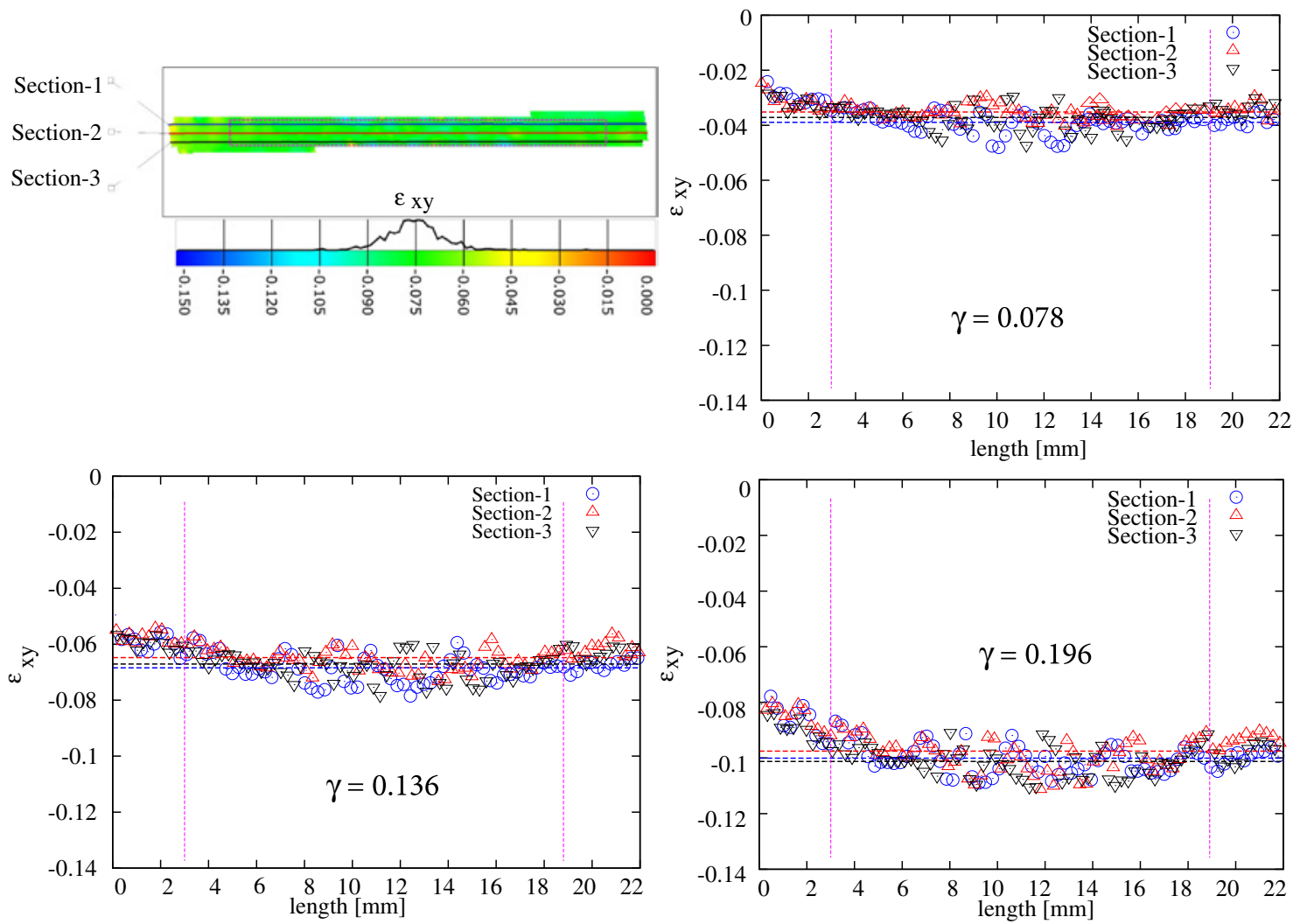

Fig. 7 Analysis of the homogeneity of the shear strain distribution along several sections parallel to the shear direction, for different values of the global shear strain. $\gamma$ is calculated in the region where the distribution is homogeneous. The curve above the color legend shows the whole distribution of the shear strain in the image for $\gamma=0.136$
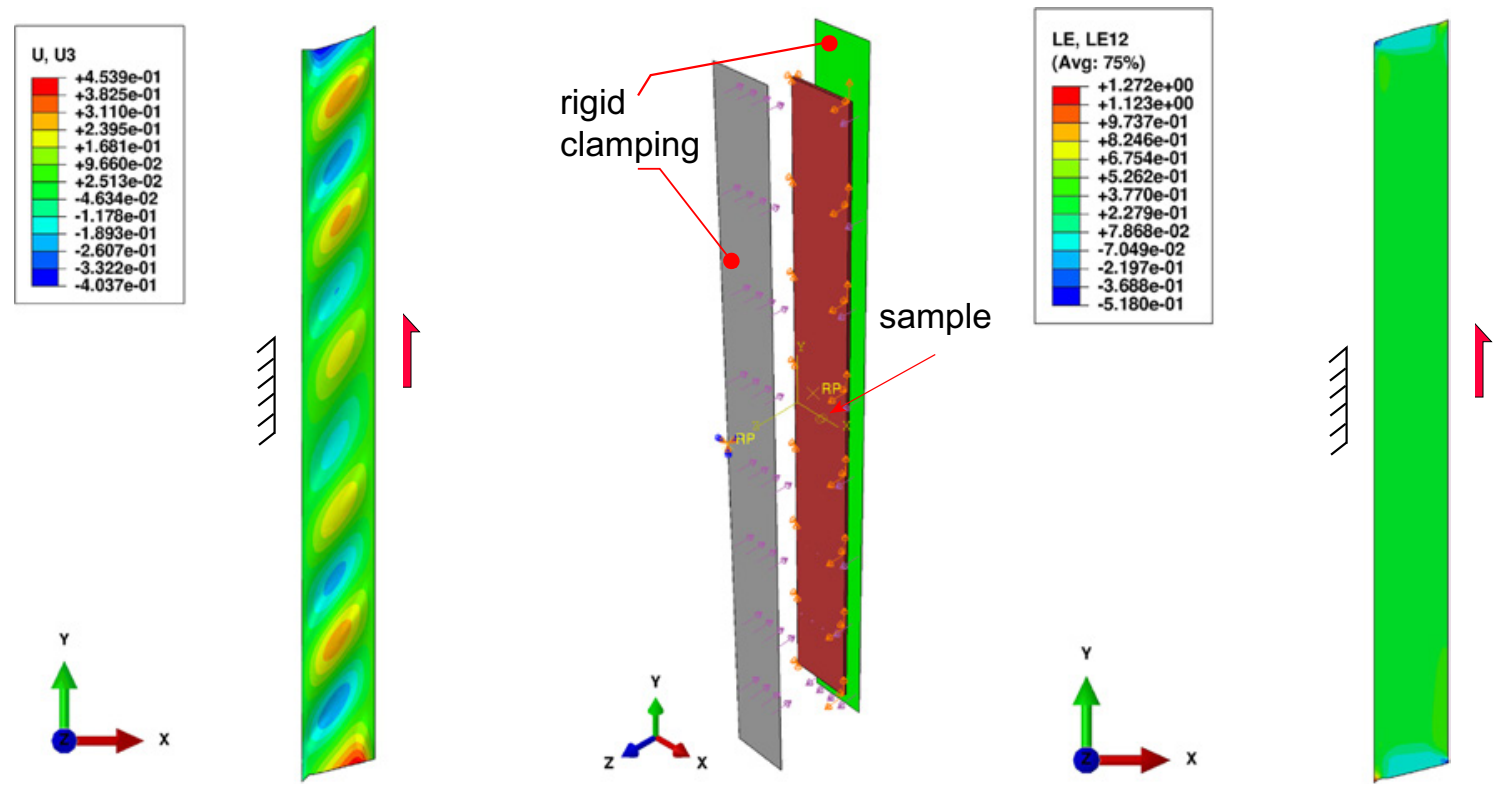

Fig. 8 Numerical simulation of the planar simple shear test. From left to right: without support, buckling effects appear for a small value of shear strain $(\gamma \geq 0.07)$, addition of the two plates to represent the experimental boundary conditions of the support, and right, shear test with support up to $(\gamma=0.33)$ without buckling 


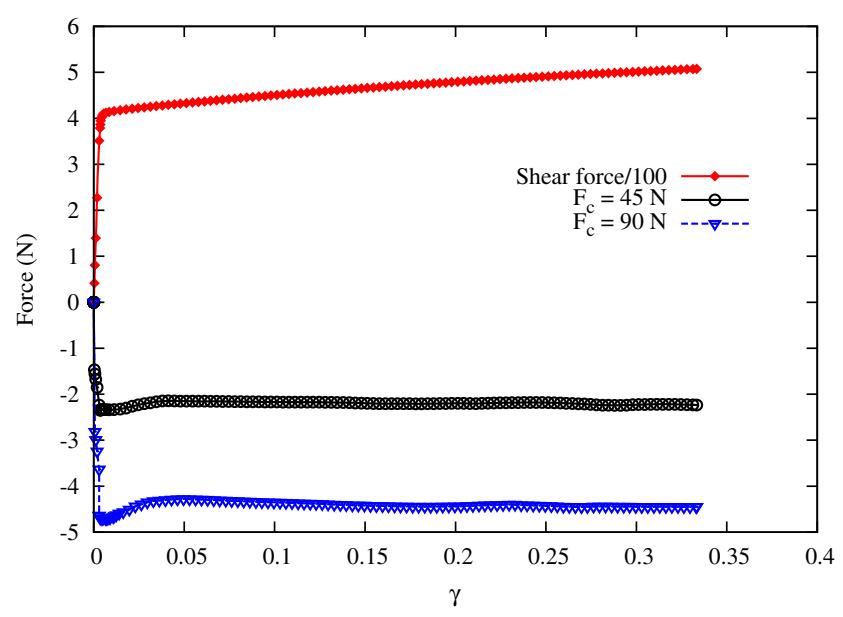

Fig. 9 Numerical simulation of the influence of the clamping force on the sliding force generated on the sample outside the shearing boundary conditions, compared to the shearing force

Figure 10 clearly highlights that the Bauschinger effect (a lower absolute yield stress at reversed loading) occurs for all pre-strain levels. Furthermore, for the largest pre-strain, a transient effect appears during reloading that is characterized by a stagnation of the hardening rate. This transient effect is not observed for lower pre-strains and in all cases, the curves converge to the equivalent monotonic curve which means that this material does not present permanent softening. This stagnation of the hardening rate during reloading is mainly associated with two physical mechanisms. Firstly, after strain reversal, the motion of the dislocations is facilitated by the dislocation substructure developed during the loading. Secondly, during reloading, the material exhibits intense dislocation annihilation leading to a

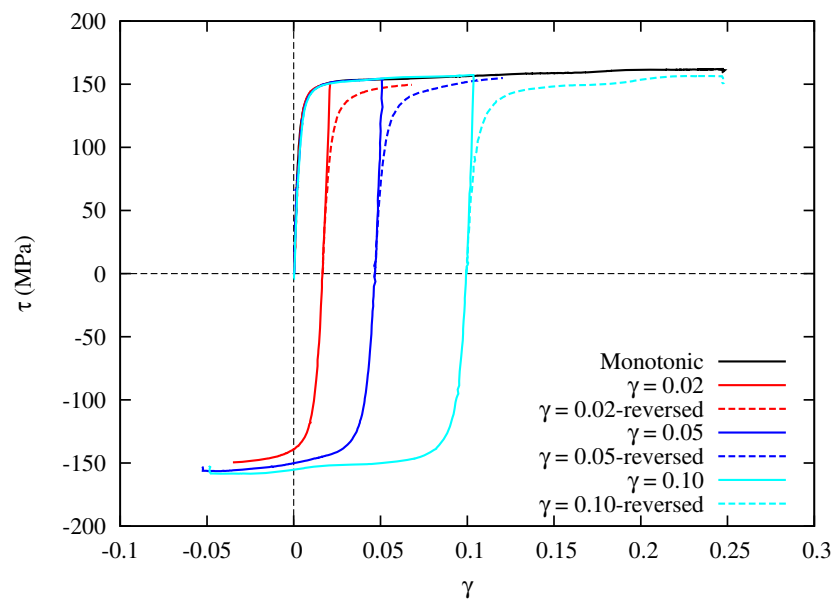

Fig. 10 Flow curves for reversed shear tests up to several values of the prestrain $(\gamma=0.02,0.05,0.1)$ superposed with a monotonic shear test on the $\mathrm{Cu}$ sheet $0.1 \mathrm{~mm}$ thick. Dashed lines correspond to the reversed curves of the shear tests plotted in cumulated shear strain dissolution of the preexisting substructure. In all cases, this transient behavior disappears when the density of the newly activated dislocations is high enough to permit resumption of work-hardening. This result is in good agreement with [36], who observed the same pre-strain dependence on an aluminum alloy subjected to tension-compression tests, but for much lower pre-strains.

\section{Conclusion}

A new simple shear test dedicated to ultra-thin metallic sheets has been proposed through the development of a specific support. The transparent glass part allows a normal tightening force to prevent the out-of-plane buckling of the sheets while also allowing full field strain measurements of the specimen using the Digital Image Correlation (DIC) method. The main results are:

- The capabilities of the device were confirmed by comparing the data obtained in a simple shear test on an austenitic stainless steel (AISI 304) with a thickness of $0.15 \mathrm{~mm}$ with and without the support. A good reproducibility of the flow curves is observed with the support and shear strains up to $\gamma=0.5$ are reached without buckling.

- The influence of friction due to the contact between the sample and the support was checked by finite elements simulations. The friction force was shown to be weak compared to the shear force, so its influence can be ignored during the test.

- Monotonic simple shear tests on a pure copper sheet with a thickness of $0.10 \mathrm{~mm}$ were performed up to rupture without buckling using this device, these were not conceivable without the support. For the first time on such a material, shear strains up to $\gamma=0.25$ were reached.

- Reversed shear tests were performed for several values of the pre-strain without buckling, that exhibit both the Bauschinger effect and transient effect characterized by a stagnation of the hardening rate during reloading for higher pre-strains that could not have been investigated previously in tension-compression tests.

Such a test is a good alternative to complex devices that have been developed recently in tension-compression to characterize kinematic hardening contributions of constitutive laws.

Acknowledgments The French Agence Nationale de la Recherche (ANR) is gratefully acknowledged for funding this work under the project ANR-12-RMNP-0009-02 as well as Delta Composants for providing the materials. The authors would like to thank A. Jégat for his collaboration and S. Thuillier for the useful discussions. 


\section{References}

1. Vollertsen F, Schulze Niehoff H, Hu Z (2006) State of the art in micro forming. Int J Mach Tools Manuf 46:1172-1179

2. Weiss B, Gröger V, Khatibi G, Kotas A, Zimprich P, Stickler R, Zagar B (2002) Characterization of mechanical and thermal properties of thin cu foils and wires. Sensors Actuators A Phys 99:172-182

3. Engel U, Eckstein R (2002) Microforming - from basic research to its realization. J Mater Process Technol 125-126:35-44

4. Tsai M, Chen Y, Wu C, Chen F (2005) Size-effects in micro-metal sheet forming of unalloyed copper and brass. Adv Mater Res 68:705-712

5. Gau JT, Principe C, Yu M (2007) Springback behavior of brass in micro sheet forming. J Mater Process Technol 191:7-10

6. Kals TA, Eckstein R (2000) Miniaturization in sheet metal working. J Mater Process Technol 103:95-101

7. Costache E, Nanu N, Chirita B, Brabie G (2013) Prediction and prevention of material cracking in the case of micro or milli drawn parts made from aluminium foils. Int J Mech Sci 69:125-140

8. Peng L, Hu P, Lai X, Mei D, Ni J (2009) Investigation of micro/meso sheet soft punch stamping process - simulation and experiments. Mater Des 30:783-790

9. Fu MW, Chan WL (2012) A review on the state-of-the-art microforming technologies. Int J Adv Manuf Technol 67:2411-2437

10. Qin Y, Ma Y, Harrison CS, Brockett A, Zhou M, Zhao J, Law F, Razali A, Smith R, Eguia J (2008) Develoment of a new machine system for the forming of micro-sheet products. Int J Mater Form Suppl 1:475-478

11. Razali AR, Qin Y (2013) A review on micro-manufacturing, micro-forming and their key issues. Procedia Engineering 53:665672

12. Fu M, Yang B, Chan W (2013) Experimental and simulation studies of micro blanking and deep drawing compound process using copper sheet. J Mater Process Technol 213:101-110

13. Michel JF, Picart P (2003) Size effects on the constitutive behavior for brass in sheet metal forming. $\mathrm{J}$ Mater Process Technol 141:439-446

14. Vollertsen F, Biermann D, Hansen HN, Jawahir IS, Kuzman K (2009) Size effects in manufacturing of metallic components. CIRP Ann Manuf Technol 58:566-587

15. Dodd B, Bai Y (1987) Ductile fracture and ductility. Academic Press, London, pp 2-28

16. Tiesler N (2002) Microforming size effects in friction and their influence on extrusion processes. Wire 1:34-38

17. Ragai I, Lazim D, Nemes JA (2005) Anisotropy and springback in draw-bending of stainless steel 410: experimental and numerical study. J Mater Process Technol 166:116-127

18. Kuwabara T, Kumanto Y, Ziegelheim J, Kurasaki I (2009) Tension-compression asymmetry of phosphor bronze for electric parts and its effect on bending behaviour. Int J Plast 25:17591776
19. Libura T, Kowalewski ZL, Dietrich L, Socha G (2016) Antibuckling system for flat specimens investigations under cyclic tension-compression. Materials Today: Proceedings 3:1045-1050

20. Boger RK, Wagoner RH, Barlat F, Lee MG, Chung K (2005) Continuous, large strain, tension/compression testing of sheet material. Int J Plast 21:2319-2343

21. Cao J, Lee W, Cheng HS, Seniw M, Wang HP, Czung K (2009) Experimental and numerical investigation of combined isotropickinematic hardening behaviour of sheet metals. Int J Plast 25:942972

22. Knoerr L, Sever N, McKune P, Faath T (2014) Cyclic tension compression testing of AHSS flat specimens with digital image correlation system. AIP Conf Proc 1567:654-658

23. Chen Z, Maekawa S, Takeda T (1999) Bauschinger effect and multiaxial yield behavior of stress-reversed mild steel. Metall Mater Trans A 30:3069-3078

24. Brown GM (1970) Inelastic deformation of an aluminum alloy under combined stress at elevated temperature. J Mech Phys Solids 18:383-396

25. Wu PD, Neale KW, Van der Giessen E (1996) Simulation of the behaviour of fcc polycrystals during reversed torsion. Int J Plast 12:1199-1219

26. Manach PY, Couty N (2002) Elastoviscohysteresis constitutive law in convected coordinate frames: application to finite deformation shear tests. Comput Mech 28:17-25

27. Bouvier S, Haddadi H, Levee P, Teodosiu C (2006) Simple shear tests: experimental techniques and characterization of the plastic anisotropy of rolled sheets at large strains. J Mater Process Technol 172:96-103

28. Thuillier S, Manach PY (2009) Comparison of the workhardening of metallic sheets using tensile and shear strain paths. Int J Plast 25:733-751

29. Boni S, G'Sell C (1982) Microscopic in situ observation of the plastic deformation of polybutene-1 films under simple shear. Polym Test 3:3-24

30. Pham CH, Thuillier S, Manach PY (2015) Mechanical properties involved in the micro-forming of ultra-thin stainless steel sheets. Metall Mater Trans A 46:3502-3515

31. Southwell RV, Skan SW (1924) On the stability under shearing forces of a flat elastic strip. Proc R Soc Lond 105:582-607

32. Chen B, Sivakumaran K (2011) Post-buckling shear strength of thin steel plates. Procedia Engineering 14:641-647

33. Weiss M, Kupke A, Manach PY, Galdos L, Hodgson PD (2015) On the Bauschinger effect in dual phase steel at high levels of strain. Mater Sci Eng A 643:127-136

34. Geng L, Wagoner RH (2002) Role of plastic anisotropy and its evolution on springback. Int J Mech Sci 44:123-148

35. Eggertsen P.-A., Mattiasson K (2009) On the modelling of the bending-unbending behaviour for accurate springback predictions. Int J Mech Sci 51:547-563

36. Proudhon H, Poole WJ, Wang X, Brechet Y (2008) The role of internal stresses on the plastic deformation of the $\mathrm{Al}-\mathrm{Mg}-\mathrm{Si}-\mathrm{Cu}$ alloy AA6111. Phil Mag 88:621-640 